\title{
Large mesospheric ice particles at exceptionally high altitudes
}

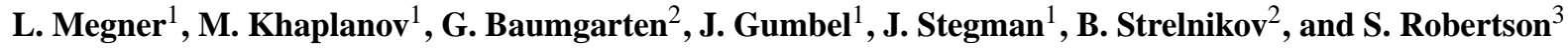 \\ ${ }^{1}$ Department of Meteorology, Stockholm University, Stockholm, Sweden \\ ${ }^{2}$ Leibniz-Institute of Atmospheric Physics, Kühlungsborn, Germany \\ ${ }^{3}$ Department of Physics, University of Colorado, Boulder, CO, USA
}

Received: 23 October 2008 - Revised: 3 February 2009 - Accepted: 3 February 2009 - Published: 2 March 2009

\begin{abstract}
We here report on the characteristics of exceptionally high Noctilucent clouds (NLC) that were detected with rocket photometers during the ECOMA/MASS campaign at Andøya, Norway 2007. The results from three separate flights are shown and discussed in connection to lidar measurements. Both the lidar measurements and the large difference between various rocket passages through the NLC show that the cloud layer was inhomogeneous on large scales. Two passages showed a particularly high, bright and vertically extended cloud, reaching to approximately $88 \mathrm{~km}$. Long time series of lidar measurements show that NLC this high are very rare, only one NLC measurement out of thousand reaches above $87 \mathrm{~km}$. The NLC is found to consist of three distinct layers. All three were bright enough to allow for particle size retrieval by phase function analysis, even though the lowest layer proved too horizontally inhomogeneous to obtain a trustworthy result. Large particles, corresponding to an effective radius of $50 \mathrm{~nm}$, were observed both in the middle and top of the NLC. The present cloud does not comply with the conventional picture that NLC ice particles nucleate near the temperature minimum and grow to larger sizes as they sediment to lower altitudes. Strong up-welling, likely caused by gravity wave activity, is required to explain its characteristics.
\end{abstract}

Keywords. Atmospheric composition and structure (Aerosols and particles; Cloud physics and chemistry; Middle atmosphere - composition and chemistry)

\section{Introduction}

Noctilucent clouds (NLC) consist of thin ice particle layers that appear at altitudes of typically $\sim 83 \mathrm{~km}$ at high latitudes in the polar summer. Interest in these clouds is in particular due to their potential role as tracer for mesospheric processes and variability. Information about water vapour and temperature trends, gravity wave action, wind patterns and even about coupling between the two hemispheres can be gained from NLC studies (Witt, 1962; Thomas et al., 1989; Karlsson et al., 2007). Thus, once the processes governing their formation are understood, they can provide an important tool for monitoring the summer mesopause region. Remote sensing by satellite and lidars provides long time series which enables for climatologies of NLC particle layers. Rocket-borne in situ measurements, on the other hand, are needed to study the local character of the clouds. We here report on photometer measurements from two rocket flights (MASS1 and ECOMA3) during NLC conditions and one flight (MASS2) in the absence of NLC. The rockets were launched from Andøya Rocket range, Norway $\left(69^{\circ} \mathrm{N}\right)$, on 3 August 2007, 22:51:20 UT (MASS1), 3 August 2007, 23:22:00 UT (ECOMA3) and on 6 August, 22:56:00 UT (MASS2). The primary optical photometer data is the scattered sunlight from the NLC ice particles. The measured radiance as a function of altitude and solar scattering angle is used to derive detailed NLC profiles and particle size information. The results are discussed and compared with NLC observations by lidar and temperature measurements from the CONE instrument. For details on the other experiments on board the rockets see Robertson et al. (2009); Rapp et al. (2009).

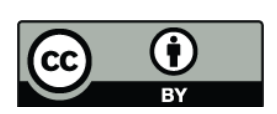

Correspondence to: L. Megner

(linda@misu.su.se)

Published by Copernicus Publications on behalf of the European Geosciences Union. 


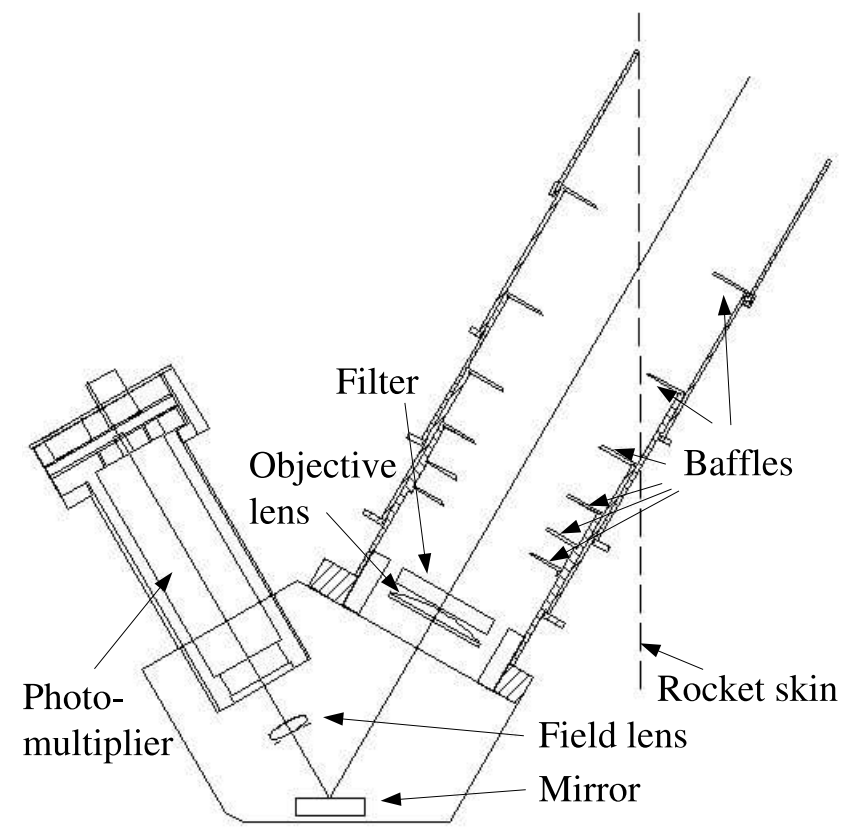

Fig. 1. Design of the ECOMA photometer. Important new features are the compact bent geometry and the extendable baffle system.

\section{Instrumentation and method}

\subsection{The photometers}

The photometers were a redevelopment of instruments used in earlier campaigns (e.g. Gumbel et al., 2001). The main changes consisted of a new improved baffle system and, for the ECOMA photometer, a different optical design due to size restrictions on this payload. The principle design of the ECOMA photometer is shown in Fig. 1. The optical system of both photometers consists of an objective lens and a field lens to focus the image onto a photomultiplier cathode. An interference filter was placed in front of the objective lens to select the wavelength interval $220 \pm 18 \mathrm{~nm}$ where contribution from the NO gamma band is small. The field of view of the instrument was $\pm 1.5^{\circ}$. The very confined space requirements on the ECOMA rocket necessitated a new folded design of the optical system. This was obtained by placing a mirror in-between the two lenses. The disadvantage of this design is the polarisation sensitivity that a mirror may introduce, but laboratory measurements showed that this effect was negligible. On both rockets, a baffle system consisting of six consecutive baffles was used to shield the photomultiplier from direct sunlight and stray light from the atmosphere. A telescopic construction of the baffle system was developed in order to extend the first baffle beyond the geometrical constraints of the payload and shield the photometer from reflections off the rocket body. The baffle was in a compressed position until the rocket skin was opened, when springs were used to push the baffle system to its extended position, where it reached out passed the rocket skin. The photometers were mounted at an angle of $30^{\circ}$ to the rocket spin axis, thus scanning the sky in the forward direction. The spin rate was $2 \mathrm{~Hz}$ for the MASS rockets and $4 \mathrm{~Hz}$ for the ECOMA rocket. At the passage through the cloud this corresponds to an altitude resolution of approximately $0.5 \mathrm{~km}$ and $0.25 \mathrm{~km}$, respectively.

The photometer detects the scattered sunlight from the total cloud column in front of it. As the rocket penetrates the cloud the vertical structure of the NLC is obtained by differentiating the photometer signal with respect to altitude. Prior to differentiation, the brightness is corrected for the longer line of sight associated with non-vertical measurement geometry. As the rocket spins, a scan through various scattering angles is obtained, from which the phase function and information of the size of the particles can be inferred (Gumbel et al., 2001).

The ECOMA rocket remained in a position where the photometer was pointing upward throughout the flight, so that measurement could be obtained on both the upleg and downleg. The MASS rocket, on the other hand, had an attitude control system, which turned the rocket so that it faced downward during the downleg. This was crucial for the MASS instrument to work properly. However, in such a position the photometer is saturated by the bright Earth, and only the upleg photometer data is therefore used in the MASS analysis. Hence, a total of four profiles were collected from the three flights.

\subsection{The lidar}

The ALOMAR RMR-lidar is a twin lidar system with two identical tiltable power lasers and two tiltable telescopes. The power-lasers emit simultaneously the wavelengths of $355 \mathrm{~nm}, 532 \mathrm{~nm}$, and $1064 \mathrm{~nm}$ with a peak power of $160 \mathrm{MW}$. A detailed description can be found in von Zahn et al. (2000). Using the two telescopes - with a diameter of $1.8 \mathrm{~m}$ each - in different directions, the lidar can observe an NLC layer in two separate sounding volumes to study the horizontal variations of the NLC layer (Baumgarten et al., 2002b). The lidar is capable of observing the cloud particle size throughout the NLC layer from the backscattering at the three wavelengths (Baumgarten and Fiedler, 2008). During the ECOMA/MASS campaign one of the telescopes was pointing close to the rocket trajectory at the NLC layer while the other telescope was sounding vertically. From the ALOMAR observatory at $379 \mathrm{~m}$ altitude the North-WestTelescope (NWT) pointed towards azimuth $333^{\circ}$ and zenith angle $13.5^{\circ}$. This configuration resulted in a horizontal displacement of the lidar beam from the ECOMA upleg trajectory of only $1.9 \mathrm{~km}$ to $2.0 \mathrm{~km}$ from $80 \mathrm{~km}$ to $90 \mathrm{~km}$ altitude. For the MASS rocket, corresponding distances were $10 \mathrm{~km}$ and $12 \mathrm{~km}$ for 80 and $90 \mathrm{~km}$, respectively. 


\subsection{The CONE temperature measurement}

The CONE (COmbined measurements of Neutrals and Electrons) instrument (see Giebeler et al., 1993) is basically a spherical ionisation gauge for the measurement of neutral density. It is surrounded by two (negatively and a positively) biased grids to shield the gauge from ambient plasma. The CONE measurements allow for the detection of small-scale density fluctuations, which arise due to processes like neutral air turbulence (Lübken et al., 2002). The height profile of neutral number densities can be integrated assuming hydrostatic equilibrium to yield a temperature profile at $\sim 200 \mathrm{~m}$ altitude resolution and an accuracy of $\sim 3 \mathrm{~K}$ (Rapp et al., 2001, 2002).

\section{NLC structure}

Figure 2 shows the measured non-differentiated signal for the four passages through the NLC layer. The photometer views the bright cloud above, and as the rocket penetrates the cloud layer, the signal drops. The drop is clearly seen for all passages where NLC were present (MASS1, ECOMA up- and downleg). The downleg signal of the ECOMA flight shows an increase of signal with altitude around $84 \mathrm{~km}$. Such an increase can be explained by a vertically inhomogeneous ice layer. The straight profile of the MASS2 flight shows that no NLC were present. The vertical gradient of this line is due to background such as Rayleigh scattering by air molecules and possible contributions from weak unidentified particle layers. The background, that is the gradient of this line, is clearly small as compared to the strength of the cloud, and is neglected in the analysis.

Figure 3 shows the vertical structure of the NLC from (a) the MASS1 upleg, (b) ECOMA3 upleg, and (c) ECOMA3 downleg. Both upleg measurements show two striking features: the vertically extended, layered structure of the NLC and the exceptional height (extending above $87 \mathrm{~km}$ ). MASS1 shows the brightest cloud formation with 3 clear peaks centred at 82,84 and $86 \mathrm{~km}$. To the authors' knowledge, only one prior in situ measurement of such high clouds exist (Witt et al., 1976), but those clouds were very weak, indicating small (or very few) particles. The extraordinary nature of these clouds is thus their brightness in combination with their height. The time difference between MASS1 and ECOMA3 was $31 \mathrm{~min}$. At a prevailing mesospheric wind speed of $\sim 50 \mathrm{~m} / \mathrm{s}$ (see Fig. 15 in Baumgarten et al., 2009) this corresponds to a distance of approximately $90 \mathrm{~km}$. The fact that the MASS1 and the ECOMA3 data both show similar structures thus indicate a large horizontal extent of the high NLC. However, the ECOMA3 downleg data show only one single narrow layer centred at $85.5 \mathrm{~km}$. The horizontal distance between the upleg and downleg is approximately $50 \mathrm{~km}$. The cloud layer thus displays large horizontal variations on this

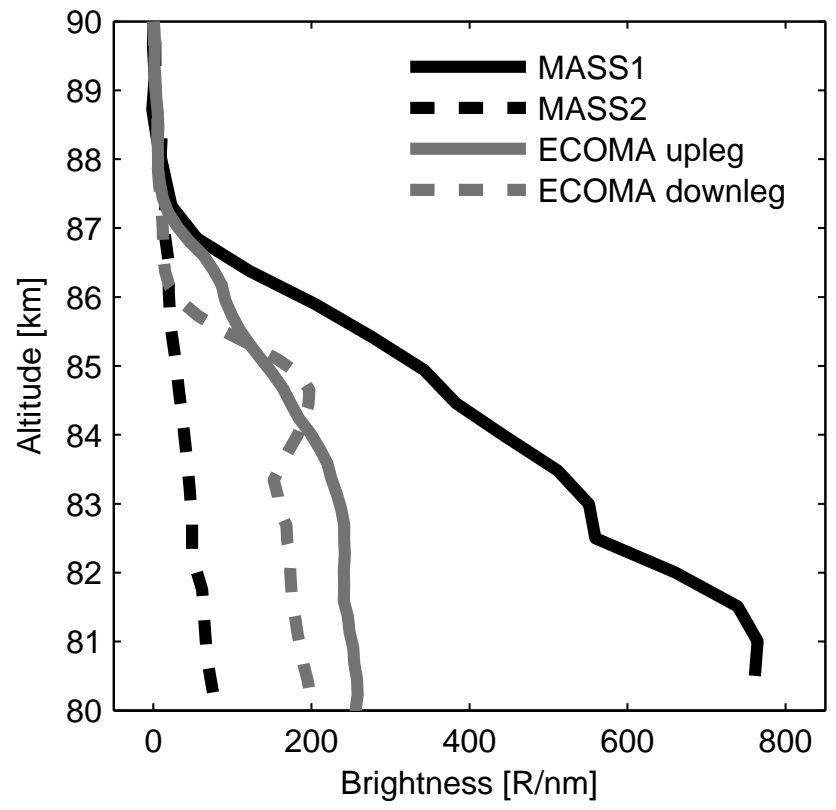

Fig. 2. Brightness (non-differentiated column radiance) at $55^{\circ}$ solar scattering angle for the four different measurements. The cloud passage is characterised by a general strong decrease of signal with respect to increasing altitude, much exceeding the slow decrease of the background Rayleigh signal. The straight line of the MASS2 measurement clearly shows the absence of NLC during this flight. The background stray light remaining at $90 \mathrm{~km}$ has been subtracted.

scale, which is also confirmed by the lidar measurements (see Sect. 5) and camera photographs (Baumgarten et al., 2009).

The temperature was measured on the downleg of the ECOMA flight by the CONE instrument (Strelnikov et al., 2009). The profile is shown as a thin gray line in Fig. 3c. The coldest temperature of $115 \mathrm{~K}$ is reached at $85 \mathrm{~km}$, above which the temperature rises sharply. The temperature minimum thus appears approximately $3-5 \mathrm{~km}$ lower than average for summer mesopause conditions at these latitudes (Lübken, 1999). This unusually low altitude of the temperature minimum is likely caused by strong gravity wave fluctuations within the region.

\section{Particle characteristics}

As mentioned in the introduction, the spinning of the rocket allows determination of the scattering phase function of the particle population. Lacking a priori information about the particle shape we assume their scattering to be represented by Mie theory (Bohren and Huffman, 1983). The scattering phase function can thus be used to retrieve information about the size of the particles, if assumptions about the size distribution are made. Pre-conditions for this analysis is that the payload attitude is well known and that the cloud can be considered horizontally homogeneous over the volume scanned 

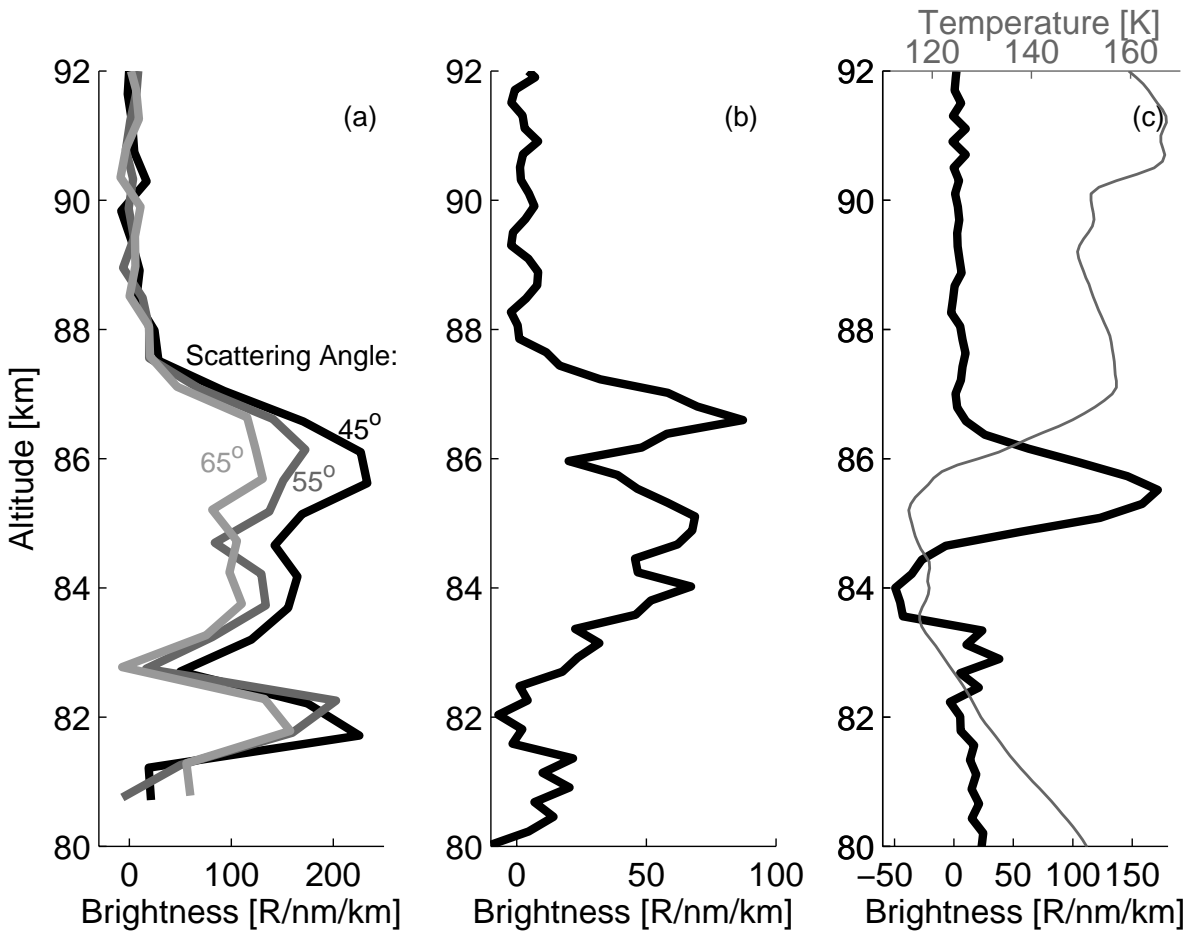

Fig. 3. Vertical NLC profiles. Panel (a) shows the MASS1 upleg for three different scattering angles. The vertically extended structure with three peaks is seen at all angles, and as expected the signal decreases with scattering angle. Panel (b) displays the ECOMA upleg. This also shows a high and extended structure. Attitude problems at lower altitudes together with the noise level make it unclear if the structure below $82 \mathrm{~km}$ is real or not. Panel (c) shows the ECOMA downleg profile, one single confined layer centred at $85.5 \mathrm{~km}$. Temperature from the CONE instrument (Strelnikov et al., 2009), also measured on the downleg, is shown by the thin gray line in (c).

by the photometer. Unfortunately, technical problems with the magnetometer on the ECOMA rocket meant that attitude data was not sufficiently accurate to perform this analyses.

The photometer on the MASS rocked scanned solar scattering angles from approximately $40^{\circ}$ to $110^{\circ}$. The phase functions at three different altitudes $(82,84$ and $86 \mathrm{~km})$ in the cloud are shown in Fig. 4. Each scattering angle is encountered twice per rocket spin, in two different viewing directions. This provides an opportunity to check the horizontal homogeneity of the cloud layer. The data sets obtained from the two different viewing directions are displayed as blue and green markers, respectively. For the top two layers, Fig. 4a and $b$, both data sets overlap. This is evidence of a homogeneous cloud layer and, hence, a trustworthy phase function can be retrieved. However for the lowest layer, the two data sets deviate from each other. This is a sign of horizontally inhomogeneous clouds and prevents a useful particle size retrieval. The lines in the figure represent the theoretical scattering phase functions from monodisperse spheres of various radii. We call the radius, which scattering function best represents that of the ice layer, the effective optical scattering radius of the ice layer. The particle distributions of the two layers are remarkably similar, and both can be represented by an effective optical scattering radius of ap- proximately $50 \pm 7 \mathrm{~nm}$. If anything, the particles at the top of the cloud appear to be slightly larger. Earlier studies (von Savigny et al., 2005; Baumgarten et al., 2007; Hervig et al., 2009a; Baumgarten et al., 2008) have shown that particles are smaller at the top of the NLC than at the base, which agrees well with the idea that the particles form at the top, and grow as they sediment to lower levels. The present NLC thus appears special also in this regard.

The effective optical scattering radius does not represent a mean particle radius. Instead it is strongly biased towards the larger side of the particle distribution. It is therefore sensitive to the assumed distribution. In Fig. 4 a monodisperse distribution of spheres was assumed. The real distribution is most likely better described by a Gaussian distribution (Rapp and Thomas, 2006). In Fig. 5 we again show the phase function of the cloud layer at $\sim 86 \mathrm{~km}$. Assuming a Gaussian ice particle distribution with a width of $14 \mathrm{~nm}$ (comparable to what is typically measured by lidar for weak NLC; Baumgarten et al., 2008), the retrieved mean radius is $30 \pm 5 \mathrm{~nm}$. The yellow line representing this is almost in-distinguishable from the solid black line. Hence, from this data it is not possible to judge which of these representations is the most appropriate. 

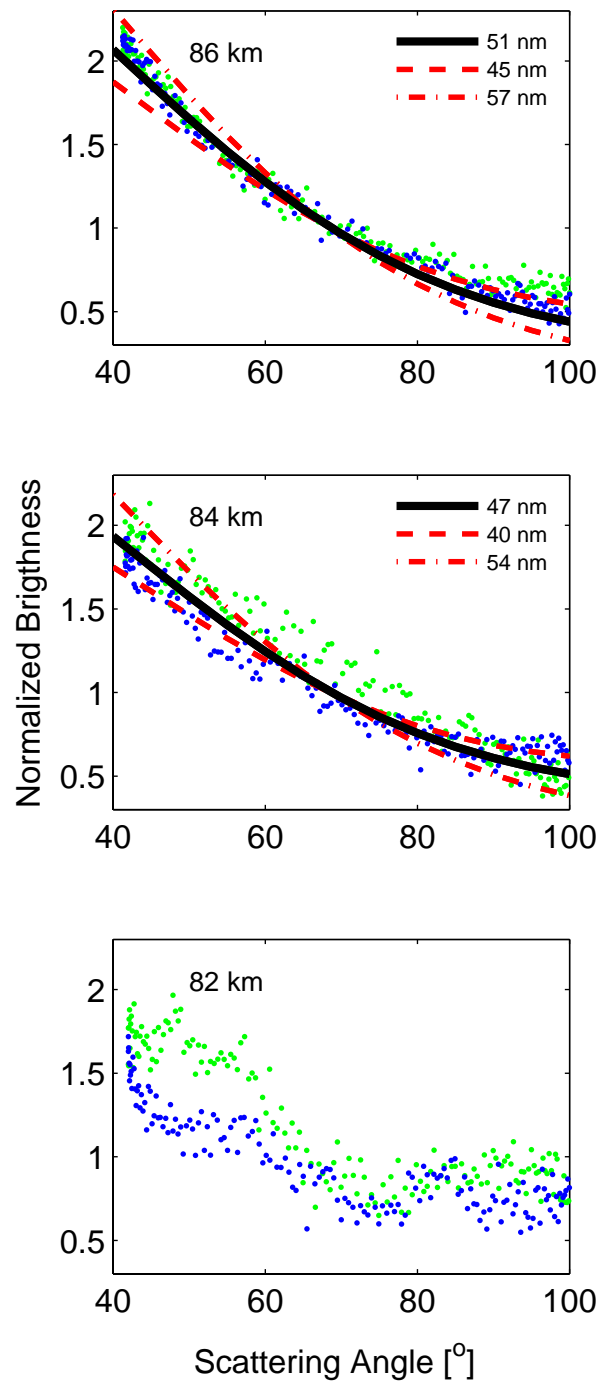

Fig. 4. Scattering phase functions for the three layers of the NLC observed on MASS1. The lines show the theoretical phase function from a monodisperse distribution of spherical particles of various radii. For the layer centred at $82 \mathrm{~km}$ the inhomogeneity of the cloud layer prevents particle size retrieval.

The above analysis has assumed a population of spherical ice particles. Historically, this assumption has been used in both microphysical modelling and optical studies of NLC particles. However, recent work suggests that the particles are non-spherical, even though the degree of deviation from spheres is not clear (Baumgarten et al., 2002a; Rapp et al., 2007; Hervig et al., 2009b). We will therefore investigate whether effects of non-spherical particles can be identified in the data. Following Mischenko and Travis (1998) we define the axial ratio (AR) as the ratio between the polar and equatorial axis, so that oblate particles are represented as $\mathrm{AR}>1$ and needle-like particles as $\mathrm{AR}<1$. Theoretical phase functions of a monodisperse distribution of spheroids with axis

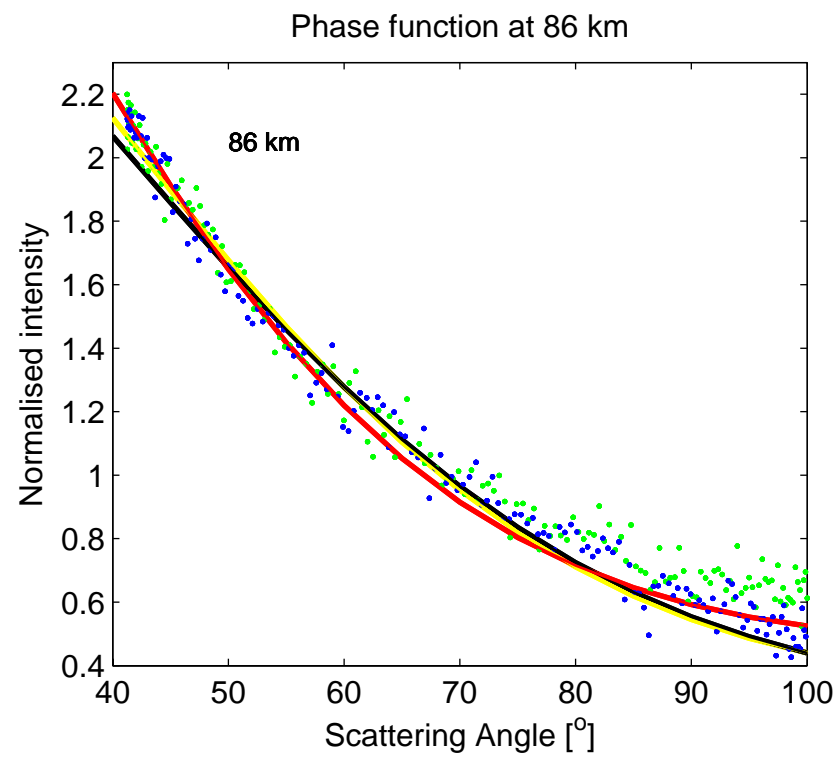

Fig. 5. Scattering phase function for the layer centred at $86 \mathrm{~km}$ compared to theoretical descriptions. The lines show the theoretical phase function for different ice particle distributions. The black line is the same as in the top panel of Fig. 4, i.e. the phase function of a monodisperse distribution of spheres of $51 \mathrm{~nm}$ radius. The yellow line represents the the phase function for a Gaussian distribution of spheres with mean radius $r=30 \mathrm{~nm}$ and $\sigma=14 \mathrm{~nm}$. The red line represents the scattering phase function of a monodisperse distribution of non-spherical particles with axis ratio of 1:4 and volume equivalent radius $r=49 \mathrm{~nm}$.

ratios of $0.25,0.5,1,2$ and 4 were examined. The best fit to data was obtained using an axis ratio 0.25 . This is shown as a red line in Fig. 5. The fit is clearly better than the black line, thus favouring needle-like particles. However, measurements at scattering angles below $40^{\circ}$ or polarisation sensitive measurements would be needed to verify this result.

From the absolute radiance from the cloud the ice particle number density can be calculated based on the assumptions about the size distribution. Assuming a Gaussian distribution with a mean of $30 \mathrm{~nm}$ and a width of $14 \mathrm{~nm}$ thus results in $\sim 30$ particles $\mathrm{cm}^{-3}$, whereas a monodisperse distribution of $50 \mathrm{~nm}$ radius results in $\sim 10 \mathrm{~cm}^{-3}$. It should be noted that the $\sim r^{6}$ dependence in the scattering cross-section makes this method of determining the number density insensitive to the smaller particles. This is the reason why these numbers are not comparable to the larger number of small particles detected by the MASS and ECOMA instruments (Robertson et al., 2009; Rapp et al., 2009).

\section{Lidar measurements}

Although the lidar was operating during the time of the flights, the sounding of the NLC layer was hindered by low 


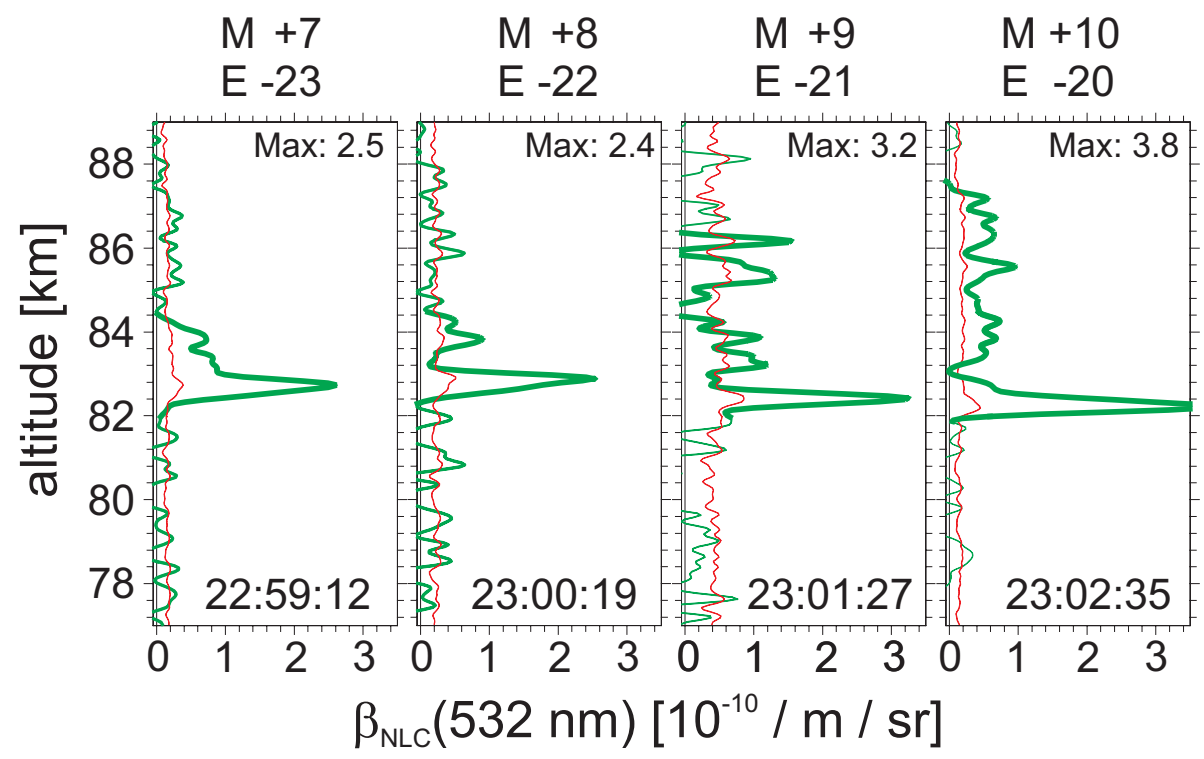

Fig. 6. Lidar backscatter ratio above ALOMAR shortly after the MASS1 and prior to the ECOMA 3 launch. The time in minutes relative to the MASS and ECOMA 3 launch is indicated above the panels. Green lines show the measured backscatter coefficients, red lines are the error of the measurement calculated from the photon noise level. Thick green lines indicate the presence of NLC.

altitude tropospheric clouds. Through some holes in the tropospheric clouds limited measurements were performed. Figure 6 shows a series of measurements from the vertically sounding telescope shortly after the MASS1, and prior to the ECOMA3, launch. It shows a single layer centred at 82$83 \mathrm{~km}$ altitude. These measurements are from straight above the ALOMAR observatory and thus at a distance of approximately $30 \mathrm{~km}$ from the MASS and ECOMA upleg passages of the NLC. Figure 6 shows the measurements from the telescope that was pointing towards the rocket trajectory and thus sampled a cloud volume close to those of the rockets. It is clear that the NLC displays a large variability both in distance and in time. The profile acquired $7 \mathrm{~min}$ after the MASS launch confirms the vertically extended structure observed by the MASS rocket. The profiles acquired closest in time to the ECOMA launch also indicate a multiple layer structure of the NLC, similar to the results from the photometer, but the statistics is limited due to an observation time of only 10 ss. Between 22:33 and 22:48 the lidar could perform particle size soundings at the peak of the NLC layer $(82.7 \mathrm{~km})$ and observed a mean particle size of $r=34 \pm 15 \mathrm{~nm}$, with standard deviation of $s=15 \pm 6 \mathrm{~nm}$ and an estimated corresponding particle number density of $42 \pm 40 \mathrm{~cm}^{-3}$. Investigation of the horizontal structure of the NLC layer by camera from Trondheim showed that the NLC layer was highly structured with very intense wave structures south-east of ALOMAR (Baumgarten et al., 2009), so a detailed comparison to the rocket results is challenging.

\section{Discussion}

The NLC reported here displays unusual features; exceptionally high altitude, a large altitudinal span, and similar particle sizes at different levels within the cloud. The cloud layer was shown to exhibit large variations over both distance and time. Two out of three passages through the layer show a cloud reaching from approximately 81 to $88 \mathrm{~km}$, with the highest peak centred at, and above, $86 \mathrm{~km}$. Long time lidar records show that only $1 \%$ of the observed NLC peaks occur above $86 \mathrm{~km}$ (Fiedler et al., 2009). In the literature there is one report of in situ measurements of NLC at these altitudes, but those were weak (Witt et al., 1976) and only spanned an altitude range of $3 \mathrm{~km}$. NLCs up to $90 \mathrm{~km}$ have recently been observed by the Solar Occultation For Ice Experiment (SOFIE) on board the AIM satellite (Russell III et al., 2009; Hervig et al., 2009a). However, SOFIE measures the occultation, which is proportional to $r^{3}$, whereas the photometer registers scattered light, proportional to $r^{6}$. Occultation measurements are therefore more sensitive to smaller particles and dimmer clouds than photometers. The extraordinary feature about the NLC reported here is thus its brightness at very high altitudes. This could be due to an extremely high number density of ice particles, but the $\sim r^{6}$ dependence in the scattering function rather suggests unusually large particles. This is confirmed by the particle size retrieval, which indeed shows unusually large particles at the top of the NLC, and similar particle sizes at different heights within the cloud.

Generally, NLC observations show smaller particles at the top of the cloud, which is easily explained by the idea that 


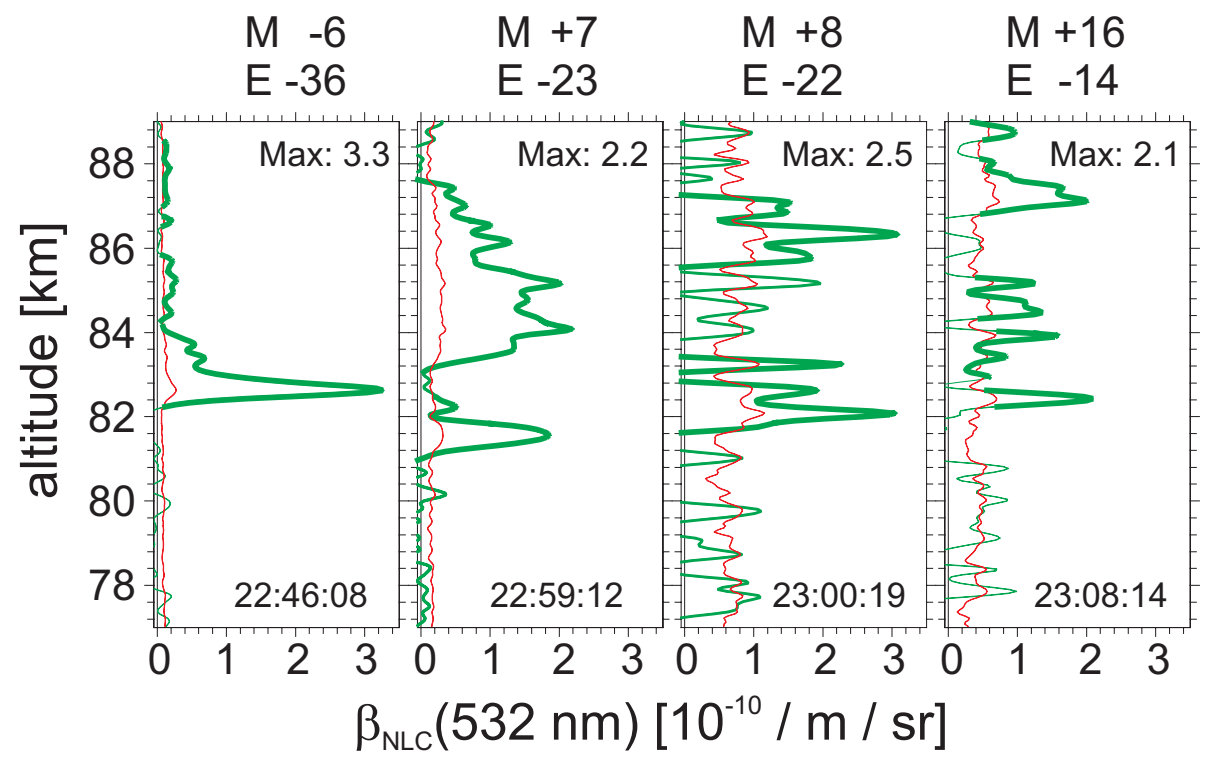

Fig. 7. Lidar back scatter ratio $\sim 20 \mathrm{~km}$ north of ALOMAR around the time of MASS launch and prior to the ECOMA3 launch. The time in minutes relative to the MASS and ECOMA3 launch is indicated above the panels. Green lines show the measured backscatter coefficients, red lines are the error of the measurement calculated from the photon noise level. Thick green lines indicate the presence of NLC. The NLC display is very variable around the time of launch, which suggests inhomogeneities in the cloud. The statistics is limited due to insufficient clearings in the tropospheric clouds.

particles nucleate near the temperature minimum and grow as they sediment to lower altitudes, so that the maximum brightness occurs a few kilometres below the mesopause (e.g. Jensen and Thomas, 1988; Berger and von Zahn, 2007). The present cloud does not comply with this idea and forces us to adapt a more complex picture. Nucleation may for instance have occurred far away from the cloud formation as argued by von Zahn and Berger (2003); Berger and von Zahn (2007) or at a lower layer from which the particles have been lifted by the vertical wind. A mechanism describing the latter, in which ice particles grow as they are transported by the gravity waves, has been suggested and modelled by Rapp et al. (2002). They argue that the size of the particle is dependent on how long it stays in the supersaturated region. The model shows that particles that sediment to the lower part of the cloud may be brought back up by the vertical wave transport, thereby prolonging the time in the supersaturation region, and allowing for further growth.

The third passage of the NLC layer, the downleg of the ECOMA flight, shows a thinner NLC, centred at $85.5 \mathrm{~km}$. The temperature measurements retrieved during this passage show an unusually cold $(115 \mathrm{~K})$ and unusually low mesopause $(85 \mathrm{~km})$, above which the temperature increases rapidly. The fact that the maximum brightness appears right at the temperature minimum, and not a few kilometres below, once again suggests unconventional particle growth. It may, especially given the cold temperature, indicate that the time scale of particle growth is shorter than the period of the wave causing the low temperature minimum. On the other hand presence of large particles may also be explained by strong up-welling within the cloud region.

\section{Summary and conclusions}

Two passages through the NLC layer showed a vertically extended NLC profile reaching from 81 to $88 \mathrm{~km}$. Particle size retrieval was possible during one of these passages and showed particles of approximately $50 \mathrm{~nm}$ radius assuming a monodisperse distribution, and $30 \mathrm{~nm}$ assuming a Gaussian size distribution with a width of $14 \mathrm{~nm}$. From the cloud brightness the corresponding number densities were calculated to $\sim 10$ particles $\mathrm{cm}^{-3}$ and $\sim 30$ particles $\mathrm{cm}^{-3}$, respectively. Lidar observations indicated similar sizes and number densities. It is important to remember that the $\sim r^{6}$ dependence in the scattering cross-section makes this method of determining a number density insensitive to the smaller particles. These effective "optical" number densities should therefore not be compared to instruments that measure nanometre-size particles. Indications of needle-like particles were observed but the lack of observations from smaller scattering angles prevented a conclusive verification of this result. The third passage through the NLC showed a thinner layer situated right at the temperature minimum. The difference between the upleg and downleg measurements as well as the variability in the lidar measurements indicate a large-scale inhomogeneity of the cloud layer. This was 
confirmed by the ground-based camera observations. However, the similarity between the upleg measurements of the two rockets, separated by a distance of $90 \mathrm{~km}$, showed that the high altitude of the clouds was not a local phenomena. All observed layers indicate unconventional particle growth that can be explained by strong gravity wave activity and associated disturbed mesopause conditions. The in situ temperature measurements of an unusually cold and low mesopause support this conclusion.

Acknowledgements. We are most thankful to input and discussions from our colleagues who took part in the ECOMA/MASS campaign. We thank Georg Witt and Liisa Petrykowska for their help with designing and preparing the instrument. We also gratefully acknowledge the immediate support of Andøya Rocket Range, NASA, and ALOMAR staff during the campaign. This project partly received research funding from the European Community's 6th Framework Program under the project "ALOMAR eARI" (RITA-CT-2003-506208). The ECOMA project has been funded by the German Space Center under DLR-grant 50 OE0301.

Topical Editor C. Jacobi thanks two anonymous referees for their help in evaluating this paper.

\section{References}

Baumgarten, G. and Fiedler, J.: Vertical structure of particle properties and water content in noctilucent clouds, Geophys. Res. Lett., 35, L10, doi:10.1029/2007GL033084, 2008.

Baumgarten, G., Fricke, K. H., and von Cossart, G.: Investigation of the shape of noctilucent cloud particles by polarization lidar technique, Geophys. Res. Lett., 29, 1630, doi:10.1029/ 2001GL013877, 2002a.

Baumgarten, G., Lübken, F.-J., and Fricke, K. H.: First observation of one noctilucent cloud by a twin lidar in two different directions, Ann. Geophys., 20, 1863-1868, 2002b, http://www.ann-geophys.net/20/1863/2002/.

Baumgarten, G., von Cossart, G., and Fiedler, J.: The size of noctilucent cloud particles above ALOMAR $\left(69^{\circ} \mathrm{N}, 16^{\circ} \mathrm{E}\right)$ : optical modeling and method description, Adv. Space Res., 40, 772784, 2007.

Baumgarten, G., Fiedler, J., and F.-J. Lübken, G. v. C.: Particle properties and water content of noctilucent clouds and their interannual variation, J. Geophys. Res., 113, D06203, doi:10.1029/ 2007JD008884, 2008.

Baumgarten, G., Fiedler, J., Fricke, K. H., Gerding, M., Hervig, M., Hoffmann, P., Müller, N., Pautet, P., Rapp, M., Robert, C., Rusch, D., von Savigny, C., and Singer, W.: The noctilucent cloud (NLC) display during the ECOMA/MASS sounding rocket flights on August 3, 2007: Morphology on global to local scales, Ann. Geophys., in press, 2009.

Berger, U. and von Zahn, U.: Three-dimensional modeling of the trajectories of visible noctilucent cloud particles: An indication of particle nucleation well below the mesopause, J. Geophys. Res., 112, D16204, doi:10.1029/2006JD008106, 2007.

Bohren, C. F. and Huffman, D. R.: Absorption and scattering of light by small particles, Wiley, New York, 1983.
Fiedler, J., Baumgarten, G., and Lübken, F.-J.: NLC observations during one solar cycle above ALOMAR, J. Atmos. Sol. Terr. Phys., in press, doi:10.1016/j.jastp.2008.11.010, 2009.

Giebeler, J., Lübken, F.-J., and Nägele, M.: CONE - a new sensor for in-situ observations of neutral and plasma density fluctuations, Proceedings of the 11th ESA Symposium on European Rocket and Balloon Programmes and Related Research, Montreux, Switzerland (ESA SP), pp. 311-318, 1993.

Gumbel, J., Stegman, J., Murtagh, D. P., and Witt, G.: Scattering Phase Functions and Particle Sizes in Noctilucent Clouds, Geophys. Res. Lett., 28(8), 1415-1418, doi:10.1029/ 2000GL012414, 2001.

Hervig, M. E., Gordley, L. L., Russell III, J. M., and Bailey, S. M.: SOFIE PMC observations during the northern summer of 2007, J. Atmos. Sol. Terr. Phys., in press, doi:10.1016/j.jastp.2008.08. 010, 2009a.

Hervig, M. E., Gordley, L. L., Stevens, M. H., Russell III, J. M., Bailey, S. M., and Baumgarten, G.: Interpretation of SOFIE PMC measurements: Cloud identification and derivation of mass density, particle shape, and particle size, J. Atmos. Sol. Terr. Phys., in press, doi:10.1016/j.jastp.2008.07.009, 2009 b.

Jensen, E. and Thomas, G. E.: A Growth-Sedimentation Model of Polar Mesospheric Clouds: Comparions with SME Measurements, J. Geophys. Res., 93, 2461-2473, 1988.

Karlsson, B., Körnich, H., and Gumbel, J.: Evidence for interhemispheric stratosphere-mesosphere coupling derived from noctilucent cloud properties, Geophys. Res. Lett., 34, L16806, doi: 10.1029/2007GL030282, 2007.

Lübken, F.-J.: Thermal structure of the Arctic summer mesosphere, J. Geophys. Res., 104, 9135-9149, 1999.

Lübken, F.-J., Rapp, M., and Hoffmann, P.: Neutral air turbulence and temperatures in the vicinity of polar mesosphere summer echoes, J. Geophys. Res., 107(D15), 4273, doi:10.1029/2001JD000915, 2002.

Mischenko, M. and Travis, L. D.: Capabilities and limitations of a current FORTAN implementation of the T-matrix method for randomly oriented, rotationally symmetric scatterers., J. Quant. Spectrosc. Radiat. Trans., 60, 309-324, 1998.

Rapp, M. and Thomas, G. E.: Modeling the microphysics of mesospheric ice particles - Assessment of current capabilities and basic sensitivities, J. Atmos. Sol. Terr. Phys., 68, 715-744, 2006.

Rapp, M., Gumbel, J., and Lübken, F.-J.: Absolute density measurements in the middle atmosphere, Ann. Geophys., 19, 571-580, 2001, http://www.ann-geophys.net/19/571/2001/.

Rapp, M., Lübken, F.-J., Müllemann, A., Thomas, G. E., and Jensen, E. J.: Small-scale temperature variations in the vicinity of NLC: Experimental and model results, J. Geophys. Res., 107(D19), 4392, doi:10.1029/2001JD001241, 2002.

Rapp, M., Thomas, G. E., and Baumgarten, G.: Spectral properties of mesospheric ice clouds: evidence for nonspherical particles, J. Geophys. Res., 112, D03211, doi:10.1029/2006JD007322, 2007.

Rapp, M., Strelnikova, I., Strelnikov, B., Latteck, R., Baumgarten, G., Li, Q., Megner, L., Gumbel, J., Friedrich, M., Hoppe, U.P., and Robertson, S.: First in situ measurement of the vertical distribution of ice volume in a mesospheric ice cloud during the ECOMA/MASS rocket-campaign, Ann. Geophys., 27, 755-766, 2009, http://www.ann-geophys.net/27/755/2009/.

Robertson, S., Horányi, M., Knappmiller, S., Sternovsky, Z., Holzworth, R., Shimogawa, M., Friedrich, M., Torkar, K., Gumbel, J., 
Megner, L., Baumgarten, G., Latteck, R., Rapp, M., and Hoppe, U.-P.: Mass analysis of charged aerosol particles in NLC and PMSE during the ECOMA/MASS campaign, Ann. Geophys., in press, 2009.

Russell III, J. M., Bailey, S. M., Gordley, L. L., Rusch, D. W., Horanyi, M., Hervig, M. E., Thomas, G. E., Randall, C. E., Siskind, D. E., Stevens, M. H., Summers, M. E., Taylor, M. J., Englert, C. R., Espy, P. J., McClintock, W. E., and Merkel, A. W.: The aeronomy of ice in the mesosphere (AIM) mission: Overview and early science results, J. Atmos. Sol. Terr. Phys., in press, doi: 10.1016/j.jastp.2008.08.011, 2009.

Strelnikov, B., Rapp, M., Strelnikova, I., Engler, N., and Latteck, R.: Small scale structures in neutrals and charged aerosol particles as observed during the ECOMA/MASS rocket campaign, Ann. Geophys., in press, 2009.

Thomas, G. E., Olivero, J. J., Jensen, E. J., Schröder, W., and Toon, O. B.: Relation between Increasing Methane and the Presence of Ice Clouds at the Mesopause, Nature, 338, 490-492, 1989. von Savigny, C., Petelina, S. V., Karlsson, B., Llewellyn, E. J., Degenstein, D. A., Lloyd, N. D., and Burrows, J. P.: Vertical variation of NLC particle sizes retrieved from Odin/OSIRIS limb scattering observations, Geophys. Res. Lett., 32, L07806, doi: 10.1029/2004GL021982, 2005.

von Zahn, U. and Berger, U.: Persistent ice cloud in the midsummer upper mesosphere at high latitudes: three-dimensional modeling and cloud interactions with ambient water vapor, J. Geophys. Res., 108, 8451, doi:10.1029/2002JD002409, 2003.

von Zahn, U., von Cossart, G., Fiedler, J., Fricke, K. H., Nelke, G., Baumgarten, G., Rees, D., Hauchecorne, A., and Adolfsen, K.: The ALOMAR Rayleigh/Mie/Raman lidar: objectives, configuration, and performance, Ann. Geophys., 18, 815-833, 2000, http://www.ann-geophys.net/18/815/2000/.

Witt, G.: Height, structure and displacement of noctilucent clouds, Tellus, 14, 1-18, 1962.

Witt, G., Dye, J. E., and Wilhelm, N.: Rocket-borne measurements of scattered sunlight in the mesosphere, J. Atmos. Terr. Phys., 38, 223-238, 1976. 